www.jmscr.igmpublication.org

Impact Factor 5.84

Index Copernicus Value: 83.27

ISSN (e)-2347-176x ISSN (p) 2455-0450

crossref DOI: _https://dx.doi.org/10.18535/jmscr/v5i4.136

Journal Of Medical Science And Clinical Research

\title{
Rhinocerebral-Orbital Mucormycosis: Salvageable with Prompt Recognition and Treatment
}

\author{
Authors \\ Dr Vijay Bhaisare, Dr Amol Chaudhari, Dr Komal Khetwani \\ Corresponding Author \\ Dr Amol Chaudhari \\ 18, Muktai Housing Society, Pavan Nagar, Nasik Maharashtra 452010 \\ Email: amolplanet70@gmail.com
}

\begin{abstract}
A case of 10 yrs. old type 1 diabetic male, who presented with left eye orbital cellulitis and lid necrosis. After promptdiagnosis of Rhinocerebral orbital mucormycosis the patient was debulked and was started with i.v amphotericin with renal monitoring along with blood sugar control, which resulted in patient survival. Hence we conclude that inspite of intracranial extension seen in MRI, high suspicion, promptdiagnosis, improvement of general condition and early intervention can be salvageable even in poor prognosis mucormycosis cases.

Keywords: Mucormycosis, Rhizopus,Diabetic ketoacidosis.
\end{abstract}

\section{Introduction}

Mucormycosis (also known as phycomycosis and zygomycosis) is an aggressive opportunistic fungal Infection.

Although mucormycosis can affect other parts of the body such as lungs and gastrointestinal tract, this case study focuses on the rhinocerebral-orbital type. ${ }^{1}$ It is common in especially diabetic patients. Other conditions associated are multiple blood transfusions, haematological malignancies, chronic steroid abuse. ${ }^{2,3}$ Rhinocerebral-orbital mucormycosis, if associated with lid gangrene is considered prognostically poor. it is a lifethreating infection associated with significant mortality. ${ }^{4}$ Mucormycosis is difficult to diagnose early, as patients often presents with non-specific symptoms .By the time signs of orbital apex involvement develop, it is often too late to save the zpatient vision, or even patient eye or life.

\section{Pathogenesis}

Diabetic or immunocompromised patients presenting with sinus diseases. Organism invade Paranasal Sinus Mucosa. Organism reaches into the orbit or brain parenchyma (causing sinoorbital \&/or rhinocerebral infections). Invasion of blood vessels leading to tissue infarction \& massive necrosis with bone destruction. ${ }^{5-7}$ Involvement of orbital structures \& orbital apex leading to orbital apex syndrome. Further posterior extension leading to cavernous sinus thrombosis \& Brain parenchyma involvement.

\section{Case Report}

A case of 10 yr. old male, who was presented with Diminution of vision left eye since 2 months which was gradual in onset and progressive in nature. and Swelling over left eyelid with blackish discolouration. Patient is known case of diabetes 
mellitus Type 1 since 2 yrs. On examination of right eye no abnormality detected. Left eye vision was light perception Negative. Lids swollen with black necrotic eschar having oedematous margin .Conjunctiva congested \& chemosed Cornea hazy \&oedematous. Ocular movements were restricted in all gazes. Digital tension was decreased .Rest details were not appreciated. (Figure.1)on oral examination, Tongue necrosis was present. (Figure.2) Nasal Cavity was obstructed. After history and examination of the patient we suspected it as a case of mucormycosis and we get MRI brain and orbit done. At the same time we started treatment.

\section{Investigations}

MRI shows $\mathrm{B} / \mathrm{L}$ orbital cellulitis, more significant on left side with mild left proptosis. The abscess is seen in the left parasellar region with involvement of the cavernous sinus and orbital apex. The intracranial meningeal thickening and enhancement is seen in the bilateral paramedian basifrontal regions suggestive of meningitis. (Fig 3) Findings are suggestive of fungal etiology.

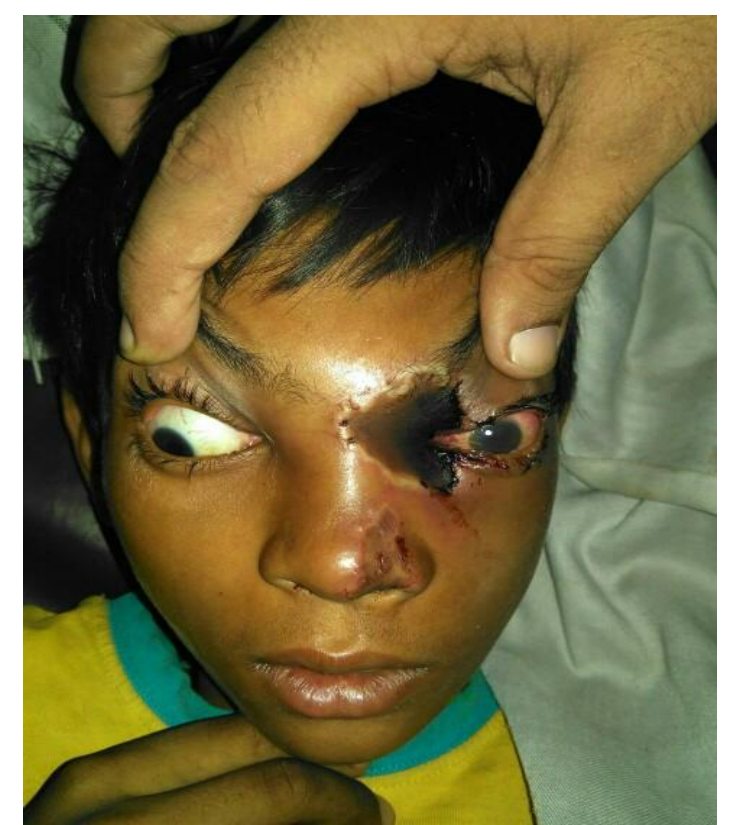

Figure1.

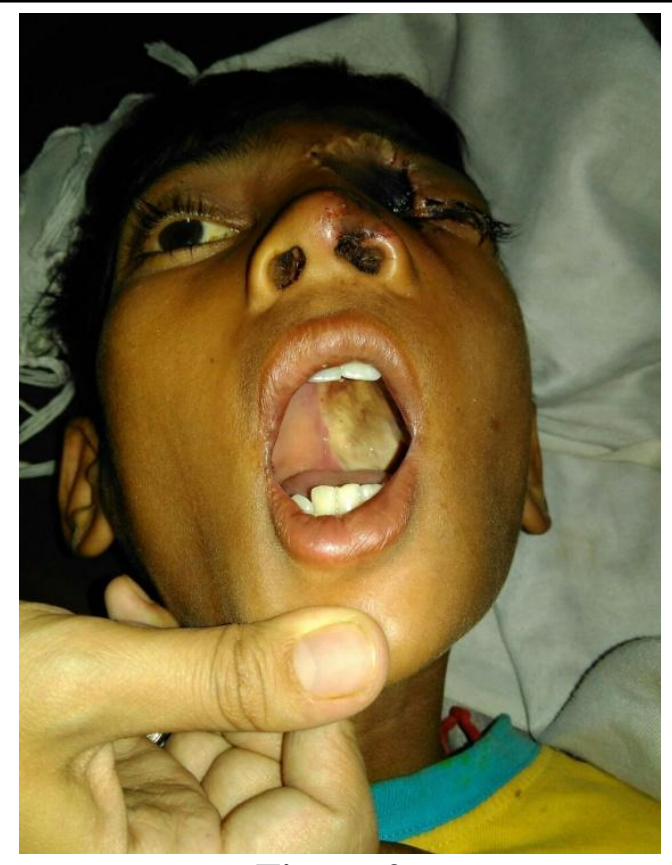

Figure 2.

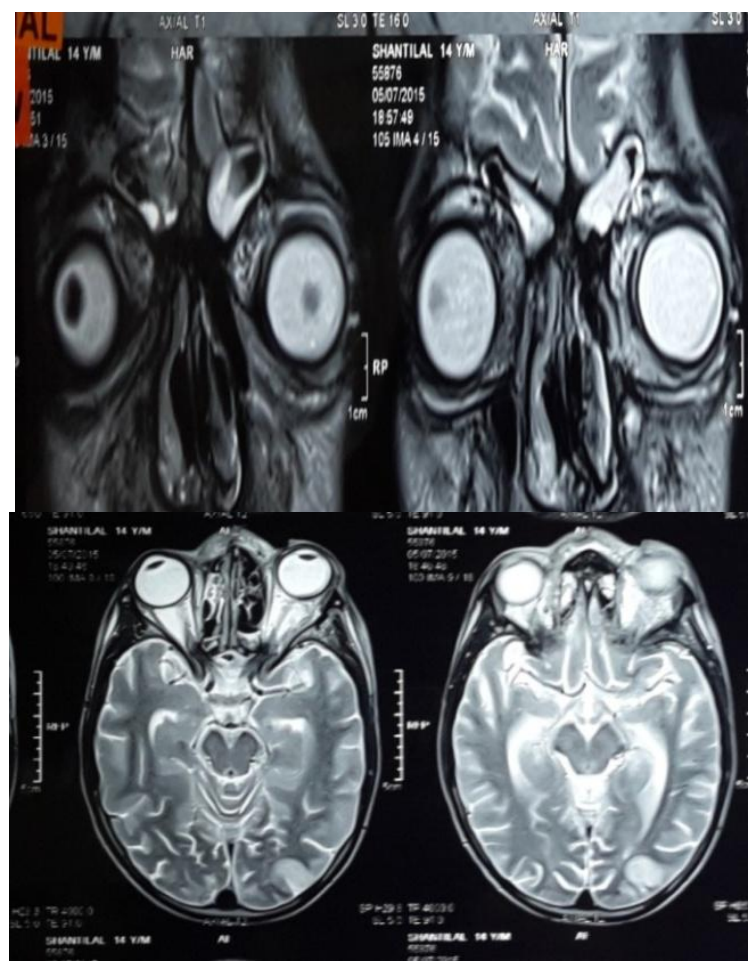

Figure 3

\section{Treatment}

After prompt diagnosis the patient was started with i.v liposomal amphotericin $4 \mathrm{mg} / \mathrm{kg}$ i.v per day for 11 days with renal monitoring along with blood sugar control. The patient underwent orbital exenteration and radical debridement of involved adjacent structures. Almost all of the necrotic and infected tissue was excised and specimen was sent for histopathological examination. The surgical 
defect was packed with amphotericin-soaked Surgical. Hence the combination of exenteration and antifungal therapy saved his life. Histopathological examination of scrapings of involved tissue were diagnostic .Broad, irregular, nonseptate hyphae with its sporangial capsule suggests Rhizopus. (Figure 4)

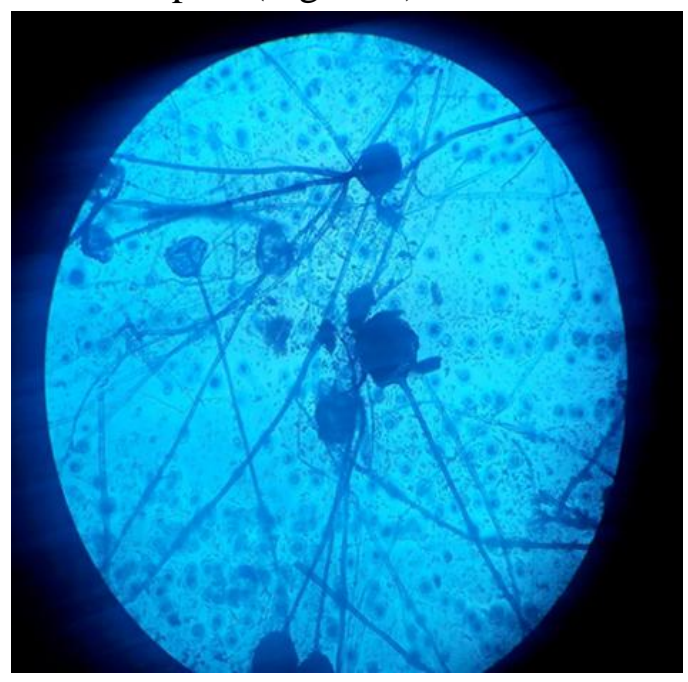

Figure 4

\section{Discussion}

Rhinocerebral mucormycosis still remains a poorly understood disease with high mortality rate. Presently, the triad of clinician's awareness, prompt initiation of treatment and timely surgical intervention represent the effective way of managing the disease. ${ }^{8}$ it is an acute opportunistic mycosis that predominantly occurs in the patients with diabetes. The clinic physician may see patients with Rhinocerebral mucormycosis in its earliest stages masquerading as other less serious diseases. Blitzer and Lawson found that in their review of 170 cases of Rhinocerebral mucormycosis, $63 \%$ of untreated diabetics died as compared with $17 \%$ mortality rate when therapy included aggressive surgery and amphotericin B administration. Absences of intracranial or orbital extension are indicators of good prognosis. Diabetic ketoacidosis at presentation is the single most important detrimental factor. The initial clinical picture might cloud the aggressive nature of the disease. ${ }^{9}$

\section{Conclusion}

This case is noteworthy as the patient came to us in poor condition but with high suspicion, prompt diagnosis, improvement of general condition, blood sugar control and early intervention is salvageable in this poor prognosis mucormycosis case and we could discharge the patient. Hence we conclude that rhinocerebral-orbital mucormycosis should be considered in all the patients with orbital inflammation associated with retinal or orbital infarction, regardless of their immunologic status because prompt surgical and medical intervention is critical and is essential for cure.

\section{References}

1. Ribes JA et al.Clin Microbial Rev.2000; 13(2):236-301.

2. Kasapoglu F et al.Otolaryngol Head Neck Surg.2010; 143(5):614-620.

3. Roden $\mathrm{MM}$ et al.Clin Infect Dis .2005; 41(5):634-653

4. Abril V, Ortega E, Segarra P, et al. Rhinocerebral mucormycosis in a patient with AIDS: a complication of diabetic ketoacidosis following pentamidine therapy. Clin Infect Dis 1996; 23:845-846.

5. Greenberg RN et al.Curr Opin Infect Dis.2004; 17(6):517-525.

6. Yohai RA et al.Surv Ophthalmol.1994; 39(1):3-22.

7. Gamaletsou $\mathrm{MN}$ et al.Curr Infect Dis Rep.2012; 14(4):423-434.

8. Bray WH, Giangiacomoj,Ide CH.Orbital apex syndrome. Surv Ophthalmol 1987; 32:136-40.

9. Lehrer RI,Howard DH,Sypherd PS,et al. Mucormycosis. Ann Intern Med 1980; 33:93-1. 